\title{
Substituição do Milho por Palma Forrageira em Dietas Completas para Vacas em Lactação 1
}

\author{
Paulo Renato Barros Araújo², Marcelo de Andrade Ferreira ${ }^{3,6}$, Lúcia Helena de Albuquerque \\ Brasil $^{3}$, Djalma Cordeiro dos Santos 4 , Rosângela Maria Brito Lima ${ }^{2}$, Antonia Sherlânea Chaves \\ Véras $^{3,6}$, Mércia Virgínia Ferreira dos Santos ${ }^{3,6}$, Safira Valença Bispo ${ }^{5}$, Marcilio de Azevedo ${ }^{3}$
}

RESUMO - Objetivou-se, com este experimento, avaliar o efeito da substituição do milho por palma forrageira sobre o desempenho de vacas mestiças em lactação e a digestibilidade dos nutrientes. Foram utilizadas oito vacas mestiças (5/8 HZ), distribuídas em dois quadrados latinos $4 \times 4$ em esquema fatorial $2 \times 2$ (duas cultivares de palma forrageira, com ou sem milho). Não houve interação entre palma e milho e o efeito dos dois alimentos foi analisado de forma isolada. Os consumos de matéria seca, de fibra em detergente ácido, dematéria orgânica, de proteína bruta, de extrato etéreo e de carboidratos totais não foram influenciados pelas cultivares de palma utilizadas. Animais que receberam palma gigante nas dietas apresentaram maior consumo de fibra em detergente neutro. As dietas com milho proporcionaram maior consumo de matéria seca ( $\mathrm{kg} / \mathrm{dia}$ e \% de PV). O consumo de NDT, os coeficientes de digestibilidade de todos os nutrientes, a produção de leite corrigida, o teor de gordura e a eficiência alimentar não foram influenciados pelas cultivares de palma forrageira ou pela inclusão milho.

Palavras-chave: consumo, digestibilidade, energia, produção de leite, semi-árido

\section{Replacement of Corn by Forage Cactus in the Total Mixed Rations for Crossbreed Lactating Cows}

\begin{abstract}
The experiment was conduced to evaluate the effects of corn replacement for forage cactus on the performance of crossbreed lactating cows and nutrient digestibility. Eight cows were assigned a two latin square design in a factorial $2 \times 2$ arrangement (two forage cactus cultivars, with or without corn).There was not interaction between forage cactus and corn and the effect of both were analyzed in an isolated way. The intake of dry matter, organic matter, acid detergent fiber, crude protein, ether extract and total carbohydrates were not affected by the forage cactus. Animals that received giant cultivar presented larger neutral detergent fiber intake. The diets with corn presented larger dry matter intake ( $\mathrm{kg} /$ day and $\%$ of $\mathrm{LW})$. The intake of TDN, the coefficients of digestibility of all nutrients, the fat corrected milk production, fat content and kg of milk: dry matter intake ratio were not affected not by the forage cactus cultivars neither by the inclusion of corn.
\end{abstract}

Key Words: digestibility, energy, intake, milk production, semi-arid

\section{Introdução}

As características climáticas do nordeste afetam diretamente a potencialidade pecuária da região, principalmente pela menor quantidade de forragens ocasionada pelas secas periódicas de maior ou menor intensidade.

A pecuária nordestina possui grande expressão econômica e social, apesar do fraco desempenho produtivo, que, em parte, é conseqüência de equívocos, como a importação de tecnologias não-adequadas à realidade local. A disponibilidade de animais e de forragem plenamente adaptados ao ambiente garante ao sistema pecuário menor risco e maior resistência às irregularidades climáticas.

$\mathrm{Na}$ época seca, há queda na disponibilidade de forragem e a maioria dos produtores tenta compensála aumentando o fornecimento de concentrado, o que além de não resolver o problema, eleva o custo de produção. A obtenção de alimentos alternativos com qualidade e disponibilidade justamente no período seco do ano para atender às exigências de mantença e produção dos animais a custo viável pode minimizar este problema.

\footnotetext{
1 Trabalho realizado por intermédio do acordo IPA/UFRPE e parcialmente financiado pela FACEPE.

2 Aluno do Programa de Pós-Graduação em Zootecnia da UFRPE.

3 Professores do Departamento de Zootecnia da UFRPE (ferreira@ufrpe.br).

${ }^{4}$ Pesquisador do IPA.

${ }^{5}$ Aluna do curso de Zootecnia da UFRPE.

${ }^{6}$ Pesquisador do CNPq.
} 
O milho é um dos principais alimentos energéticos utilizados na alimentação de bovinos, porém, apesar de ser bastante usado na dieta de monogástricos e de o Estado de Pernambuco ser importador deste produto, apresenta custo elevado.

Segundo Gomes \& Andrade (1996), entre os alimentos concentrados, o milho predomina na maioria dos confinamentos no Brasil e, apesar de seu alto valor energético, quando usado em dietas mistas de volumoso e concentrados, pode provocar efeito negativo ao reduzir a digestibilidade da fibra. $\mathrm{O}$ alto valor nutritivo do grão de milho, como produto alimentício para consumo humano, e a necessidade de seu uso na composição de rações para monogástricos, tornam seu custo elevado, levando os produtores à busca de alimentos alternativos. Dessa forma, subprodutos ricos em fibra altamente digestível têm sido avaliados como fontes alternativas de energia em substituição aos grãos ricos em amido (Anderson et al., 1988).

Redução no consumo de matéria seca por bezerros holandeses foi observada por Peixoto \& Warner (1993), ao substituírem o milho pela farinha de mandioca. Reduções no consumo de matéria seca também foram verificadas quando o milho foi substituído pela farinha de varredura de mandioca em dietas para novilhas (Marques et al., 2000). Entretanto, Zeoula et al. (2003) não observaram alteração no consumo em ovinos alimentados com dietas com níveis de substituição do milho pela farinha de mandioca de varredura.

A palma forrageira é base da alimentação do rebanho leiteiro no semi-árido pernambucano, por ser uma cultura adaptada às condições edafoclimáticas e por apresentar altas produções de matéria seca por unidade de área (Santos et al., 1997), além de excelente fonte de energia, rica em carboidratos não-fibrosos, $61,79 \%$ (Wanderley et al., 2002) e nutrientes digestíveis totais, 62\% (Melo et al., 2003). Porém, a palma apresenta baixos teores de fibra em detergente neutro, em torno de 26\%, (FDN), necessitando sua associação à uma fonte de fibra que apresente alta efetividade (Mattos et al., 2000).

Santana et al. (1972) e Santos et al. (1990), utilizando a palma como volumoso exclusivo, constataram baixas produções de leite, leite com teor de gordura reduzido, além de distúrbios digestivos, sobretudo diarréias. Recentemente, Mattos et al. (2000) e Wanderley et al. (2002) conduziram experimentos associando a palma com diferentes fontes de fibra e verificaram boas produções de leite, com teores normais de gordura e ausência de distúrbios digestivos.

Tradicionalmente, são utilizadas no Estado de Pernambuco três cultivares de palma forrageira (redonda, miúda e gigante). A miúda apresenta teor de matéria seca superior e fibra em detergente neutro inferior às demais cultivares. A palma é uma cultura de elevado potencial de produção e, para expressar esse potencial necessita de adubação, controle de plantas daninhas e densidade de plantio adequados, podendo a produção de matéria seca variar de 12 a 47 toneladas a cada dois anos (Nascimento et al., 2002).

Santana et al. (1972) compararam a palma redonda, a silagem de milho e a palma redonda + silagem de milho, fornecidos separadamente, e não encontraram diferenças significativas para a produção de leite e para porcentagem de gordura no leite, porém observaram perda de peso nos animais alimentados com palma.

Santos et al. (1990) avaliaram o desempenho de vacas holandesas na produção de leite, quando arraçoadas com as três cultivares de palma (redonda, gigante e miúda) associadas à silagem de milho, porém, com ingredientes fornecidos separadamente, e não encontraram diferenças significativas entre os tratamentos para produção de leite, leite corrigido para $4 \%$ de gordura, relação de consumo de matéria seca e leite produzido e percentagem de gordura. No entanto, verificaram que as vacas alimentadas com diferentes cultivares de palma forrageira apresentaram repetidas diarréias e, em alguns animais, houve perda de peso.

Nos trabalhos com palma forrageira na dieta de vacas leiteira publicados recentemente, a forma de fornecimento tem sido a mistura completa.

Ao avaliarem o desempenho de vacas holandesas em lactação alimentadas com rações contendo diferentes níveis de palma forrageira $(0 ; 12 ; 24 ; 36 \%)$ em substituição à silagem de sorgo, na forma de mistura completa, Wanderley et al. (2002) não encontraram diferenças significativas para produção de leite com e sem correção a 3,5\% de gordura. Não foram observados distúrbios metabólicos, como diarréias, para os níveis de palma fornecidos. Os autores ressaltaram a importância do fornecimento da palma forrageira em associação adequada com fontes de alimentos ricos em fibra, a fim de se melhorar o uso dessa forrageira.

Véras et al. (2002) observaram que a substituição de até $75 \%$ do milho pelo farelo de palma forrageira em dietas de ovinos não alterou o coeficiente de 
digestibilidade dos nutrientes e o teor de NDT. Por outro lado, Cavalcanti et al. (2002a) verificaram redução no ganho de peso de ovinos ao substituírem o milho pelo farelo de palma.

Objetivou-se, com este trabalho, avaliar o efeito da substituição do milho por duas variedades de palma forrageira (gigante e miúda) sobre o desempenho de vacas mestiças em lactação e a digestiblidade aparente dos nutrientes.

\section{Material e Métodos}

O experimento foi realizado na Estação Experimental de Arcoverde, pertencente à Empresa Pernambucana de Pesquisa Agropecuária (IPA).

Foram utilizadas oito vacas mestiças $5 / 8$ HolandêsZebu, com peso vivo médio de $490 \mathrm{~kg}$, alojadas em estábulo provido de cochos individuais, para controle do consumo de alimentos, e bebedouros. O fornecimento das dietas foi feito duas vezes ao dia na forma de mistura completa e, para garantir o consumo voluntário e manter os níveis dos diferentes ingredientes, foi permitido sobra de 5 a $10 \%$ do total de matéria seca fornecida.

$\mathrm{O}$ delineamento experimental empregado foi o quadrado latino, com quatro vacas, quatro períodos e quatro tratamentos. Foram utilizados dois quadrados de acordo com a ordem de lactação. Cada período teve duração de 21 dias sendo 14 para adaptação dos animais às dietas e sete para coleta de dados e de

Tabela 1 - Composição percentual dos ingredientes nas dietas (\% na MS)

Table 1 - Percentage of the ingredients in the diets (\% of DM)

\begin{tabular}{|c|c|c|c|c|}
\hline \multirow[t]{2}{*}{$\begin{array}{l}\text { Ingredientes } \\
\text { Ingredients }\end{array}$} & \multicolumn{4}{|c|}{$\begin{array}{c}\text { Tratamentos } \\
\text { Treatments }\end{array}$} \\
\hline & $\mathrm{PGCM}^{1}$ & PGSM $^{2}$ & $\mathrm{PMCM}^{3}$ & $\mathrm{PMSM}^{4}$ \\
\hline $\begin{array}{l}\text { Capim-elefante } \\
\text { Napiergrass }\end{array}$ & 37,00 & 37,00 & 37,00 & 37,00 \\
\hline $\begin{array}{l}\text { Palma Gigante } \\
\text { Giant forage cactus }\end{array}$ & 36,00 & 50,00 & - & - \\
\hline $\begin{array}{l}\text { Palma miúda } \\
\text { Small forage cactus }\end{array}$ & - & - & 36,00 & 50,00 \\
\hline $\begin{array}{l}\text { Concentrado } 1 \\
\text { Concentrate } 1\end{array}$ & 27,00 & - & 27,00 & - \\
\hline $\begin{array}{l}\text { Concentrado } 2 \\
\text { Concentrate } 2\end{array}$ & - & 13,00 & - & 13,00 \\
\hline
\end{tabular}

1 PGCM (palma gigante com milho) (giant forage cactus with corn). 2 PGSM (Palma gigante sem milho) (giant forage cactus without corn).

3 PMCM (Palma miúda com milho) (small forage cactus with corn).

4 PMSM (Palma miúda sem milho) (small forage cactus without corn). amostras (fezes, sobras e alimentos). Os tratamentos consistiram da combinação em arranjo fatorial de duas cultivares de palma (Gigante e Miúda) e dois níveis de milho (com e sem) (Tabela 1).

A composição dos concentrados encontra-se na Tabela 2.

As dietas com milho foram calculadas segundo o NRC (1989), para satisfazer as exigências de produção de $14 \mathrm{~kg} /$ dia, com $4 \%$ de gordura. A composição bromatológica é apresentada na Tabela 3.

A produção de leite foi avaliada pelo controle leiteiro diário. Foram realizadas duas ordenhas diárias, registrando-se a produção individual de cada animal. Foram coletadas amostras de leite das duas ordenhas em um único dia, a cada período experimental, para determinação do teor de gordura, pelo método de Gerber, descrito por Behmer (1965). Para cálculo de produção de leite corrigido para $4 \%$ de gordura, adotou-se a fórmula proposta pelo NRC (1989): $\mathrm{LCG}=0,4$ ( $\mathrm{kg}$ de leite $)+15$ ( $\mathrm{kg}$ de gordura $)$.

O coeficiente de digestibilidade aparente dos nutrientes foi determinado pela fórmula descrita por Coelho da Silva \& Leão (1979):

$\mathrm{CD}=[(\mathrm{kg}$ nutriente ingerido $-\mathrm{kg}$ nutriente excretado)/ kg nutriente ingerido] x 100

Para estimativa da produção de matéria seca fecal (PMSF), foi utilizado como indicador interno a FDA indigestível (FDAi), que foi obtida incubando-se o alimento fornecido, as sobras e as fezes por 144 horas, como descrito por Berchielli et al. (2000),

Tabela 2 - Composição percentual dos ingredientes nos concentrados (\% da MS)

Table 2 - Percentage of the ingredients in the concentrates (\% of DM)

\begin{tabular}{lcc}
\hline $\begin{array}{l}\text { Ingrediente } \\
\text { Feedstuff }\end{array}$ & \multicolumn{2}{c}{$\begin{array}{c}\text { Concentrados } \\
\text { Concentrates }\end{array}$} \\
\cline { 2 - 3 } & $\begin{array}{c}\text { Concentrado 1 } \\
\text { Concentrate 1 }\end{array}$ & $\begin{array}{c}\text { Concentrado 2 } \\
\text { Concentrate 2 }\end{array}$ \\
\hline Milho (Corn) & 56,00 & - \\
Farelo de soja (Soybean meal) & 31,00 & 69,50 \\
Sal mineral(Mineral salt) & 6,00 & 17,50 \\
Uréia (Urea) & 7,00 & 13,00 \\
\hline
\end{tabular}


Tabela 3 - Teores de matéria seca (MS), matéria orgânica (MO), proteína bruta (PB), extrato etéreo (EE), fibra em detergente neutro (FDN), fibra em detergente ácido (FDA), carboidratos totais (CHT) e NDT das dietas

Table 3 - Contents of dry matter (DM), organic matter (OM), crude protein (CP), ether extract (EE), neutral detergent fiber (NDF), acid detergent fiber (ADF), total carbohydrates (TC) and TDN of the diets

\begin{tabular}{lcccc}
\hline \multirow{2}{*}{$\begin{array}{l}\text { Itens } \\
\text { Items }\end{array}$} & \multicolumn{3}{c}{$\begin{array}{c}\text { Tratamentos } \\
\text { Treatments }\end{array}$} \\
\cline { 2 - 5 } & PGCM $^{2}$ & PGSM $^{3}$ & PMCM $^{4}$ & PMSM $^{5}$ \\
\hline MS (\%) (DM\%) & 14,46 & 11,50 & 20,16 & 16,88 \\
MO $^{1}(O M)$ & 90,89 & 88,66 & 91,01 & 91,19 \\
BB $^{1}(C P)$ & 13,40 & 13,37 & 12,92 & 12,66 \\
$\mathrm{EE}^{1}(E E)$ & 2,77 & 2,20 & 2,75 & 2,21 \\
$\mathrm{FDN}^{1}(N D F)$ & 39,64 & 39,80 & 35,83 & 35,14 \\
$\mathrm{FDA}^{1}(A D F)$ & 22,52 & 26,30 & 22,65 & 24,75 \\
$\mathrm{CHT}^{1}(T C)$ & 76,32 & 73,08 & 73,50 & 75,47 \\
NDT $^{1}(T D N)$ & 61,00 & 54,69 & 58,00 & 57,00 \\
\hline
\end{tabular}

$1 \% \mathrm{MS}(\% \mathrm{DM})$.

2 PGCM (palma gigante com milho) (giant forage cactus with corn).

3 PGSM (Palma gigante sem milho) (giant forage cactus without corn)

4 PMCM (Palma miúda com milho ) (small forage cactus with corn).

5 PMSM (Palma miúda sem milho) (small forage cactus without corn).

ressalta-se que a incubação foi in situ, de acordo com Valadares Filho (2000). O material remanescente da incubação foi submetido à extração com detergente ácido, cujo resíduo foi considerado FDAi. Para cálculo da PMSF foi utilizada a seguinte equação:

PMSF $=($ Consumo do indicador, em $\mathrm{kg}) /$

(Concentração do indicador, em \%)

A coleta de fezes foi feita diretamente no reto dos animais no $16^{\circ}$ - dia pela manhã e no $20^{\circ}$ dia à tarde (Andrade et al., 2002). As fezes foram secas a $60^{\circ} \mathrm{C}$ em estufa de ventilação forçada e, em seguida, foram feitas amostras compostas por animal e período.

Os alimentos fornecidos e suas sobras foram pesados e amostrados diariamente, durante o período de coleta, e, posteriormente, foram feitas amostras compostas por período. Essas amostras foram submetidas a análises de matéria seca (MS), matéria orgânica (MO), proteína bruta $(\mathrm{PB})$, extrato etéreo $(\mathrm{EE})$, fibra em detergente neutro (FDN) e fibra em detergente ácido (FDA) no Laboratório de Nutrição Animal do Departamento de Zootecnia da UFRPE segundo metodologia de Silva (1990), com exceção da FDN da palma e dos concentrados, determinada conforme metodologia proposta por Van Soest et al. (1991).

Os carboidratos totais (CHT) foram estimados, segundo Sniffen et al. (1992), como:

$$
\mathrm{CHT}=100-(\mathrm{PB}+\mathrm{EE}+\text { Cinzas })
$$

R. Bras. Zootec., v.33, n.6, p.1850-1857, 2004 (Supl. 1)
O consumo e teor de NDT foram estimados, segundo Sniffen et al. (1992), conforme a equação: consumo de $\mathrm{NDT}=(\mathrm{PB}$ ingerida $-\mathrm{PB}$ fecal $)+2,25$ $($ EE ingerido $-\mathrm{EE}$ fecal $)+(\mathrm{CHT}$ ingerido $-\mathrm{CHT}$ fecal $)$. NDT $(\%)=($ Consumo de NDT/Consumo de MS) x 100 .

Os dados foram submetidos à análise de variância e as médias, comparadas pelo teste F, uma vez que não houve interação entre palma e milho.

\section{Resultados e Discussão}

$\mathrm{Na}$ Tabela 4, são apresentados os resultados de consumo médio de matéria seca, de FDN e de FDA. Como não houve interação $(\mathrm{P}>0,05)$ entre palma e milho, o efeito dos dois foi analisado isoladamente.

$\mathrm{O}$ consumo de MS não foi influenciado $(\mathrm{P}>0,05)$ pelas cultivares de palma estudadas. Porém, foi verificado maior consumo $(\mathrm{P}<0,05)(\mathrm{kg} /$ dia e \% PV) para as dietas com milho, que apresentaram maior teor de matéria seca que aquelas sem milho, fator que possivelmente determinou esta diferença. Santos et al. (1997) relataram que grandes quantidades de palma podem reduzir o consumo de matéria seca, em função do alto teor de umidade presente, resultando em grandes quantidades de matéria natural. Para todos os tratamentos, o consumo verificado foi superior às recomendações do NRC (1989), de $2,82 \%$ do peso vivo. 
Quanto ao consumo de FDN, foi observada diferença $(\mathrm{P}<0,05)$ apenas em relação às cultivares de palma. Os animais que receberam dietas com palma gigante apresentaram maior consumo $(5,80 \mathrm{~kg} / \mathrm{dia} \mathrm{e}$ $1,18 \%$ do PV) em relação aos alimentados com palma miúda $(5,19 \mathrm{~kg} /$ dia e $1,05 \%$ do $\mathrm{PV})$, o que, provavelmente, está associado ao maior teor de FDN da palma gigante $(27,69 \%)$ em relação à palma miúda $(16,6 \%)$. O consumo de FDN ficou abaixo do limite de $1,2 \%$ do PV, sugerido por Mertens (1997) como fator limitante do consumo de MS em vacas em lactação. O consumo de FDA, por sua vez, não foi influenciado $(\mathrm{P}>0,05)$ pelas cultivares de palma, pela presença ou ausência do milho.

Na Tabela 5, são apresentados os resultados dos consumos médios de matéria orgânica (MO), proteína bruta (PB), extrato etéreo (EE), carboidratos-não fibrosos $\mathrm{CNF}$ ), carboidratos totais (CHT) e nutrientes digestíveis totais (NDT). Não houve interação entre palma e milho e os efeitos foram analisados de forma isolada.

Tabela 4 - Consumos médios diários de matéria seca (CMS), fibra em detergente neutro, (CFDN) e fibra em detergente ácido (CFDA)

Table 4 - Means for average daily intakes of dry matter (DMI), neutral detergent fiber (NDFI) and acid detergent fiber (ADFI)

\begin{tabular}{|c|c|c|c|c|c|}
\hline \multirow[t]{3}{*}{$\begin{array}{l}\text { Itens } \\
\text { Items }\end{array}$} & \multicolumn{4}{|c|}{$\begin{array}{c}\text { Tratamentos } \\
\text { Treatments }\end{array}$} & \multirow[t]{3}{*}{$\mathrm{CV}(\%)$} \\
\hline & \multicolumn{2}{|c|}{$\begin{array}{c}\text { Palma } \\
\text { Forage cactus }\end{array}$} & \multicolumn{2}{|c|}{$\begin{array}{l}\text { Milho } \\
\text { Corn }\end{array}$} & \\
\hline & PG & PM & $\mathrm{CM}$ & SM & \\
\hline CMS(kg/dia) (DMI, $\mathrm{kg} / \mathrm{dav})$ & 14,71 & 15,25 & $15,54 \mathrm{a}$ & $14,41 \mathrm{~b}$ & 6,39 \\
\hline CMS (\%PV) $(D M I, \% L W)$ & 3,00 & 3,09 & $3,19 \mathrm{a}$ & $2,90 \mathrm{~b}$ & 6,46 \\
\hline $\mathrm{CMS}\left(\mathrm{g} / \mathrm{kg}^{0,75}\right)\left(D M I, \mathrm{~g} / \mathrm{kg}^{\cdot 75}\right)$ & 141,45 & 145,82 & 150,12 & 137,15 & 6,44 \\
\hline CFDN (kg/dia) (NDFI, kg/day) & $5,80 \mathrm{~A}$ & 5,19B & 5,66 & 5,24 & 7,23 \\
\hline CFDN (\% PV) (NDFI, \%LW) & $1,18 \mathrm{~A}$ & $1,05 \mathrm{~B}$ & $1,16 \mathrm{a}$ & $1,05 \mathrm{~b}$ & 7,32 \\
\hline CFDA (kg/dia) (ADFI, $\mathrm{kg} /$ day $)$ & 3,62 & 3,48 & 3,46 & 3,61 & 4,43 \\
\hline
\end{tabular}

PG: palma gigante; PM: palma miúda; CM: com milho; SM: sem milho.

Médias na linha, para palma, seguidas de letra maiúscula diferente diferem entre si pelo teste $F(P<0,05)$.

Médias na coluna, para milho, seguidas de letra minúscula diferente, diferem entre si pelo teste $F(P<0,05)$.

PG: giant forage cactus; PM: small forage cactus; CM: with corn; SM: without corn.

Means within a row for forage cactus, followed by different capital letter are different $(P<.05)$ by $F$ test.

Means within a column, for corn, followed by different small letter are different $(P<.05)$ by $F$ test.

Tabela 5 - Consumos médios diários de matéria orgânica (CMO), proteína bruta (CPB), extrato etéreo (CEE), carboidratos não-fibrosos (CCNF), carboidratos totais (CCHT) e NDT (CNDT), em kg/dia

Table 5 - Means for average daily intakes of organic matter (OMI), crude protein (CPI), ether extract (EEI), total carbohydrates (TCl) and TDN (TDNI), in $\mathrm{kg} / \mathrm{day}$

\begin{tabular}{|c|c|c|c|c|c|}
\hline \multirow[t]{3}{*}{$\begin{array}{l}\text { Itens } \\
\text { Items }\end{array}$} & \multicolumn{4}{|c|}{$\begin{array}{c}\text { Tratamentos } \\
\text { Treatments }\end{array}$} & \multirow[t]{3}{*}{$\mathrm{CV}(\%)$} \\
\hline & \multicolumn{2}{|c|}{$\begin{array}{c}\text { Palma } \\
\text { Forage cactus }\end{array}$} & \multicolumn{2}{|c|}{$\begin{array}{l}\text { Milho } \\
\text { Corn }\end{array}$} & \\
\hline & PG & PM & $\mathrm{CM}$ & SM & \\
\hline $\mathrm{CMO}(O M I)$ & 13,29 & 13,98 & $14,23 \mathrm{a}$ & $13,04 \mathrm{~b}$ & 6,20 \\
\hline $\mathrm{CPB}(C P I)$ & 1,98 & 1,96 & $2,06 \mathrm{a}$ & $1,86 \mathrm{~b}$ & 7,52 \\
\hline $\operatorname{CEE}(E E I)$ & 0,37 & 0,38 & $0,43 \mathrm{a}$ & $0,32 b$ & 7,72 \\
\hline $\mathrm{CCHT}(T C I)$ & 10,94 & 11,62 & $11,73 \mathrm{a}$ & $10,81 \mathrm{~b}$ & 5,93 \\
\hline CNDT (TDNI) & 8,55 & 9,08 & 9,37 & 8,26 & 14,81 \\
\hline
\end{tabular}

PG: palma gigante; PM: palma miúda; CM: com milho; SM: sem milho

Médias na linha, para palma, seguidas de letra maiúscula diferente diferem $(P<0,05)$ entre si pelo teste $F$.

Médias na coluna, para milho, seguidas de letra minúscula diferente, diferem $(P<0,05)$ entre si pelo teste $F$.

PG: giant forage cactus; PM: small forage cactus; CM: with corn; SM: without corn.

Means within a row for forage cactus, followed by different capital letter are different $(P<.05)$ by $F$ test.

Means within a column, for corn, followed by different small letter are different $(P<.05)$ by $F$ test.

R. Bras. Zootec., v.33, n.6, p.1850-1857, 2004 (Supl. 1) 
Os consumos de $\mathrm{MO}, \mathrm{PB}, \mathrm{EE}, \mathrm{CHT}$ e NDT não foram influenciados pelas cultivares de palma utilizadas $(\mathrm{P}>0,05)$. Os consumos de $\mathrm{MO}, \mathrm{PB}$ e EE foram maiores $(\mathrm{P}<0,05)$ para as dietas contendo milho, o que pode ser explicado pelo maior consumo de MS verificado nos tratamentos que não sofreram a substituição do milho e pela variação destes nutrientes nas dietas. Em todos os tratamentos, o consumo de $\mathrm{PB}$ foi superior às exigências do NRC (1989) (1,68 kg, em média) para os animais utilizados e os níveis de produção verificados.

Para CHT, os animais que receberam dietas com milho apresentaram maior consumo $(\mathrm{P}<0,05)$, fato atribuído à maior ingestão de matéria seca.

Quanto ao consumo de NDT, não houve influência $(\mathrm{P}>0,05)$ das cultivares de palma utilizadas ou da presença ou ausência do milho. As exigências do NRC (1989) para o nível de produção observado e para animais utilizados são de, aproximadamente, $8,65 \mathrm{~kg}$ de NDT/dia. O consumo médio verificado ficou pouco acima deste valor $(8,82 \mathrm{~kg} / \mathrm{dia})$.

$\mathrm{Na}$ Tabela 6, são apresentados os coeficientes de digestibilidade aparente dos diferentes nutrientes. Como não houve interação $(P>0,05)$ entre palma e milho, o efeito dos dois alimentos foi analisado de forma isolada.

Os coeficientes de digestibilidade aparente da MS, MO, PB, EE, FDN, FDA, CNF e CHT não diferiram $(\mathrm{P}>0,05)$, em função da cultivar de palma utilizada e da inclusão ou não do milho. Cavalcanti et al. (2002b) observaram decréscimo linear na digestibilidade da $\mathrm{MS}, \mathrm{MO}, \mathrm{CHT}$ e $\mathrm{CNF}$, à medida que se incluiu farelo de palma forrageira em substituição ao milho em dietas para ovinos (0 a $100 \%)$. Fatores que podem ter concorrido para a ausência de diferença nos coeficientes de digestibilidade verificados foram a pequena participação do milho nas dietas experimentais (em torno de 15\%) e os efeitos associativos entre os ingredientes das dietas.

Na Tabela 7, são apresentados os dados referentes à produção de leite e de gordura, ao teor de gordura do leite e à eficiência alimentar. Como não houve interação entre palma e milho, o efeito dos dois foi analisado de forma separada.

Não houve diferença $(\mathrm{P}>0,05)$ para produções de leite total e corrigida; teor e produção de gordura e eficiência alimentar, em relação às cultivares de palma utilizadas. Resultados semelhantes foram encontrados por Santos et al. (1990) e Santos et al. (2001), que, ao compararem três cultivares (miúda, redonda e gigante) em dietas de vacas mestiças, concluíram não haver diferença na produção de leite. Os animais que receberam dietas com milho apresentaram maior produção $(\mathrm{PL})(\mathrm{P}<0,05) \mathrm{em}$ relação àqueles que consumiram dietas sem milho $(15,24$ vs $13,99 \mathrm{~kg} / \mathrm{dia})$, comportamento que,

Tabela 6 - Coeficientes de digestibilidade aparente de matéria seca (CDAMS), matéria orgânica (CDAMO), proteína bruta (CDAPB), extrato etéreo (CDAEE), fibra em detergente neutro (CDAFDN), fibra em detergente ácido (CDAFDA) e carboidratos totais (CDACHT)

Table 6 - Apparent digestibility coefficients of dry matter (ADCDM), organic matter (ADCOM), crude protein (ADCCP), ether extract (ADCEE), neutral detergent fiber (ADCNDF), acid detergent fiber (ADCADF) and total carbohydrates (ADCTC)

\begin{tabular}{|c|c|c|c|c|c|}
\hline \multirow[t]{3}{*}{$\begin{array}{l}\text { Itens } \\
\text { Items }\end{array}$} & \multicolumn{4}{|c|}{$\begin{array}{c}\text { Tratamentos } \\
\text { Treatments }\end{array}$} & \multirow[t]{3}{*}{$\mathrm{CV}(\%)$} \\
\hline & \multicolumn{2}{|c|}{$\begin{array}{c}\text { Palma } \\
\text { Forage cactus }\end{array}$} & \multicolumn{2}{|c|}{$\begin{array}{l}\text { Milho } \\
\text { Corn }\end{array}$} & \\
\hline & PG & PM & $\mathrm{CM}$ & SM & \\
\hline CDAMS (ADCDM) & 54,11 & 58,72 & 58,88 & 53,95 & 12,48 \\
\hline CDAMO (ADCOM) & 62,11 & 62,07 & 63,50 & 62,07 & 10,23 \\
\hline CDAPB (ADCCP) & 69,34 & 61,52 & 64,24 & 66,62 & 15,85 \\
\hline CDAEE (ADCEE) & 54,46 & 57,35 & 63,23 & 48,59 & 32,52 \\
\hline CDAFDN (ADCNDF) & 42,98 & 38,37 & 43,54 & 37,81 & 22,24 \\
\hline CDAFDA $(A D C A D F)$ & 38,11 & 43,78 & 41,38 & 40,50 & 29,24 \\
\hline CDACHT (ADCTC) & 61,14 & 63,87 & 63,87 & 61,65 & 10,08 \\
\hline
\end{tabular}

PG: palma gigante; PM: palma miúda; CM: com milho; SM: sem milho

Médias na linha, para palma, seguidas de letra maiúscula diferente diferem $(P<0,05)$ entre si pelo teste $F$. Médias na coluna, para milho, seguidas de letra minúscula diferente, diferem $(P<0,05)$ entre si pelo teste $F$. PG: giant forage cactus; PM: small forage cactus; CM: with corn; SM: without corn.

Means within a row for forage cactus, followed by different capital letter are different $(P<.05)$ by $F$ test.

Means within a column, for corn, followed by different small letter are different $(P<.05)$ by $F$ test.

R. Bras. Zootec., v.33, n.6, p.1850-1857, 2004 (Supl. 1) 
Tabela 7 - Produção de leite (PL), produção de leite corrigido a 4\% de gordura (PLCG), teor de gordura do leite (TG), produção de gordura (PG) e eficiência alimentar (EA em $\mathrm{kg}$ de leite corrigido/kg de MS consumida)

Table 7 - Milk yield (MY), fat corrected milk yield 4\% (FCMY), milk fat (MF), fat yield (FY) and FCMY:DMI ratio

\begin{tabular}{|c|c|c|c|c|c|}
\hline \multirow[t]{3}{*}{$\begin{array}{l}\text { Itens } \\
\text { Items }\end{array}$} & \multicolumn{4}{|c|}{$\begin{array}{c}\text { Tratamentos } \\
\text { Treatments }\end{array}$} & \multirow[t]{3}{*}{$\mathrm{CV}(\%)$} \\
\hline & \multicolumn{2}{|c|}{$\begin{array}{c}\text { Palma } \\
\text { Forage cactus }\end{array}$} & \multicolumn{2}{|c|}{$\begin{array}{l}\text { Milho } \\
\text { Corn }\end{array}$} & \\
\hline & PG & PM & $\mathrm{CM}$ & SM & \\
\hline PL (kg/dia) (MY kg/day) & 14,84 & 14,38 & $15,24 \mathrm{a}$ & $13,99 \mathrm{~b}$ & 4,95 \\
\hline PLCG (kg/dia) (FCMY kg/day) & 15,49 & 15,23 & 15,89 & 14,83 & 6,24 \\
\hline TG $(\%)(M F \%)$ & 4,31 & 4,39 & 4,29 & 4,41 & 3,78 \\
\hline $\mathrm{PG}(\mathrm{kg} / \mathrm{dia})(F Y \mathrm{~kg} /$ day $)$ & 0,66 & 0,66 & 0,68 & 0,65 & 7,33 \\
\hline EA (FCMY:DMI ratio) & 1,05 & 0,99 & 1,01 & 1,02 & 6,15 \\
\hline
\end{tabular}

PG: palma gigante; PM: palma miúda; CM: com milho; SM: sem milho

Médias na linha, para palma, seguidas de letra maiúscula diferente diferem $(P<0,05)$ entre si pelo teste $F$.

Médias na coluna, para milho, seguidas de letra minúscula diferente, diferem $(P<0,05)$ entre si pelo teste $F$.

PG: giant forage cactus; PM: small forage cactus; CM: with corn; SM: without corn.

Means within a row for forage cactus, followed by different capital letter are different $(P<.05)$ by $F$ test.

Means within a column, for corn, followed by different small letter are different $(P<.05)$ by $F$ test.

provavelmente, que pode ser atribuído à maior ingestão de matéria seca e de energia (NDT) observada para os tratamentos com milho.

Apesar da menor produção de leite pelos animais que receberam dietas sem milho (aproximadamente $8,5 \%$ ), deve-se atentar para a baixa utilização de concentrado nas dietas, em torno de $11,87 \%$ da matéria seca. Todavia, quando feita a correção para $4 \%$ de gordura, esta diferença desapareceu. Isto ocorreu porque o leite produzido pelas vacas recebendo dietas com milho apresentou menor teor de gordura $(4,29 v s 4,41 \%)$. Não houve efeito $(\mathrm{P}>0,05)$ das cultivares de palma e do milho sobre a produção de gordura e eficiência alimentar.

\section{Conclusões}

É possível substituir o milho por palma forrageira (cultivar gigante ou miúda), em dietas que contenham pelo menos $36 \%$ de palma, sem alteração dos coeficientes de digestibilidade, mantendo-se níveis de produção de leite e de gordura satisfatórios, com baixa utilização de concentrado na dieta.

\section{Literatura Citada}

ANDERSON, S.J.; MERRIL, J.K.; KLOPFENSTEIN, J.T. Soybean hulls as a energy supplement for the grazing ruminant. Journal of Animal Science, v.66, n.1, p.2959-2964, 1988. ANDRADE, D.K.B.; FERREIRA, M.A.; VERAS, A.S.C. et al. Digestibilidade e absorção aparentes em vacas da raça holan- desa alimentadas com palma forrageira (Opuntia ficus indica Mill) em substituição à silagem de sorgo (Sorghum bicolor (L.) Moench). Revista Brasileira de Zootecnia, v.31, n.5, p.2088-2097, 2002.

BEHMER, M.L.A. Laticínios, leite, manteiga, queijo, caseína e instalações. 3.ed. São Paulo: Melhoramentos, 1965. 294p.

BERCHIELLI, T.T.; ANDRADE, P.; FURLAY, C.L. Avaliação de indicadores internos em ensaios de digestibilidade. Revista Brasileira de Zootecnia, v.29, n.3, p.830-839, 2000.

CAVALCANTI, C.V.A.; FERREIRA, M.A.; VERAS, R.M.L. et al. Farelo de palma forrageira como fonte de energia para ovinos em crescimento. 1. Digestibilidade aparente. In: CONGRESSO DE INICIAÇÃO CIENTIFICA UFRPE, 11 , 2002a, Recife. Anais... Recife: Universidade Federal Rural do Pernambuco, 2002a. p.403-404.

CAVALCANTI, C.V.A.; FERREIRA, M.A.; VERAS, R.M. L.et al. Farelo de palma forrageira como fonte de energia para ovinos em crescimento. 2. Consumo de nutrientes. In: CONGRESSO DE INICIAÇÃO CIENTIFICA UFRPE, 11, 2002b, Recife. Anais... Recife: Universidade Federal Rural do Pernambuco, 2002b. p.405-406.

COELHO DA SILVA, J.F.C.; LEÃO, M.I. Fundamentos de nutrição de ruminantes. Piracicaba: Livroceres, 1979. 380p.

FARIAS, I.; SANTOS, D.C.; LIRA, M.A. et al.Cultivo da palma forrageira em Pernambuco: Recife: IPA, 1984. 5p (Documentos, 21).

GOMES, I.P.O.; ANDRADE, P. Níveis de substituição de milho por casca do grão de soja na dieta de bovinos. I. Desempenho em confinamento. In: REUNIÃO ANUAL DA SOCIEDADEBRASILEIRA DE ZOOTECNIA, 33., 1996, Fortaleza.Anais... Fortaleza: SBZ, 1996. p.55-57.

MARQUES, J.; PRADO, I.N.; ZEOULA, L.M. et al. Avaliação da mandioca e de seus resíduos industriais em substituição ao milho no desempenho de novilhas confinadas. Revista Brasileira de Zootecnia, v.29, n.5, p.1528-1536, 2000.

MATTOS, L.M.E.; FERREIRA, M.A.; SANTOS, D.C. Associação da palma forrageira (Opuntia fícus indica Mill) com diferentes fontes de fibra na alimentação de vacas $5 / 8$ holan-

R. Bras. Zootec., v.33, n.6, p.1850-1857, 2004 (Supl. 1) 
dês/zebu em lactação. Revista Brasileira de Zootecnia, v.29, n.6, p.2128-2134, 2000

MELO, A.A.S.; FERREIRA, M.A.; VERAS, A.S.C. et al. Substituição do farelo de soja por uréia e palma forrageira (Opuntia fícus indica Mill) em dietas para vacas em lactação.I. Desempenho. Revista Brasileira de Zootecnia, v.32, n.5, p. 727-736, 2003.

MERTENS, D.R. Creating a system for meeting the fiber requirements of dairy cows. Journal of Dairy Science, v.80., n.7, p.1463-1481, 1997.

NASCIMENTO, A.C.O.; MATTOS, C.W.; DUBEUX Jr. et al. Desempenho da palma forrageira (Opuntia ficus indica Mill) submetida a diferentes níveis de adubação em Sertânea-PE. In: CONGRESSO DE INICIAÇÃO CIENTIFICA UFRPE, 11., 2002, Recife. Anais... Recife: Universidade Federal Rural do Pernambuco, 2002. p.4389-390.

NATIONAL RESEARCH COUNCIL - NRC. Nutrient requirements of dairy cattle. 6 ed. Washington: National Academy Press, 1989. 157p.

PEIXOTO, R.R.; WARNER, R.G. Avaliação da farinha de mandioca como componente de rações para terneiros leiteiros em desaleitamento precoce. Revista Brasileira de Mandioca, v. 12 , n.1/2, p.39-47, 1993.

SANTANA, O.P.; VIANA, S.P.; ESTIMA, A.L. et al. Palma versus silagem na alimentação de vacas leiteiras. Revista Brasileira de Zootecnia, v.1, n.1, p.31-40, 1972.

SANTOS, M.V.F.; LIRA, M.A.; FARIAS, I. et al. Estudo comparativo das cultivares de palma forrageira gigante, redonda (Opuntia fícus indica Mill) e miúda (Nopalea cochenillifera Salm Dyck) na produção de leite. Revista da Sociedade Brasileira de Zootecnia, v.19, n.6, p.504-511, 1990.

SANTOS, D.C.; FARIAS, I.; LIRA, M.A. et al. A palma forrageira (Opuntia fícus indica Mill e Nopalea cochenillifera Salm Dyck) em Pernambuco: cultivo e utilização. Recife: IPA, 1997. 23p. (Documentos, 25)

SANTOS, D.C.; SANTOS, M.V.F.; FARIAS, I. et al. Desempenho produtivo de vacas $5 / 8$ holando/zebu alimentadas com diferentes cultivares de palma forrageira (Opuntia e Nopalea). Revista Brasileira de Zootecnia, v.30, n.1, p.12-17, 2001.
SILVA, D.J. Análise de alimentos (métodos químicos e biológicos). Viçosa, MG: Universidade Federal de Viçosa, 1990. 165p.

SNIFFEN, C.J.; O'CONNOR, J.D.; Van SOEST, P.J. et al. A net carbohydrate and protein system for evaluating cattle diets:II. Carbohydrate and protein availability. Journal of Animal Science, v.70, n.11, p.3562-3577, 1992.

VALADARES FILHO, S.C. Nutrição, avaliação de alimentos e tabelas de composição de alimentos para bovinos. In: REUNIÃO ANUAL DA SOCIEDADE BRASILEIRA DE ZOOTECNIA, 37., 2000, Viçosa, MG. Palestras... Viçosa, MG: Sociedade Brasileira de Zootecnia, 2000.p.267-338.

Van SOEST, P.J.; ROBERTSON, J.B.; LEWIS, B.A. Methods for dietary fiber, neutral detergent fiber, and nonstarch polysacharides in relation to animal nutrition. Journal of Dairy Science, v.74, n.10, p.3583-3597, 1991.

VÉRAS, R.M.L.; FERREIRA, M.A.; CARVALHO, F.F.R. et al. Farelo de palma forrageira (Opuntia fícus indica Mill) em substituição ao milho.1. Digestibilidade nutrientes. Revista Brasileira de Zootecnia, v.31, n.3, p.1302-1306, 2002.

ZEOULA, L.M.; CALDAS NETO, S.F.; GERON, L.J.V. et al. Substituição do milho pela farinha de varredura (Manihot sculenta) em rações de ovinos: consumo, digestibilidade, balanço de nitrogênio e energia e parâmetros ruminais. Revista Brasileira de Zootecnia, v.32, n.2, p.491-502, 2003.

WANDERLEY, W.L.; FERREIRA, M.A.; ANDRADE, D.K.B. et al. Palma forrageira (Opuntia ficus indica Mill) em substituição a silagem de sorgo (Sorghum Bicolor (L.) Moench) na alimentação de vacas leiteiras. Revista Brasileira de Zootecnia, v.31, n.1, p.273-281, 2002. 